\title{
Study on the Corrosion Behavior of Aqueous Extract of Thermal Insulation Materials to A3 Steel
}

\author{
Jiang Lin-lin ${ }^{1,2}$, Li ling-jie ${ }^{1,2}$, Zhang Hong-lei ${ }^{1,2}$, Wang Zhi-tao ${ }^{1,2}$, Zhang Yan-jun ${ }^{1,2}$ \\ ${ }^{1}$ Research Division of Anti-Corrosion Coating and Thermal Insulation Technology, CNPC Research Institute of Engineering Technology, \\ Tianjin, China \\ ${ }^{2}$ The Key Laboratory of Tubular Goods Engineering, CNPC - Research Division of Anti-corrosion Coating and Thermal Insulation Structure, \\ Tianjin, China
}

Email address:

sddyjianglinlin@163.com (Jiang Lin-lin)

\section{To cite this article:}

Jiang Lin-lin, Li Ling-jie, Zhang Hong-lei, Wang Zhi-tao, Zhang Yan-jun. Study on the Corrosion Behavior of Aqueous Extract of Thermal Insulation Materials to A3 Steel. International Journal of Materials Science and Applications. Vol. 6, No. 3, 2017, pp. $136-141$.

doi: $10.11648 /$ j.ijmsa.20170603.14

Received: March 15, 2017; Accepted: May 2, 2017; Published: May 4, 2017

\begin{abstract}
The $\mathrm{pH}$, conductivity and ions contents of aqueous extract of thermal insulation materials and deionized water were tested. Their corrosion behavior to A3 steel was investigated by static weight loss method. The results showed that the corrosion rate of glass wool was the lowest and performed local corrosion. The danger was the largest. Silica aerogel insulation blankets performed homogeneous corrosion and the corrosion rate was lower than that of deionized water. Aqueous extract of polyurethane foams expanded with $\mathrm{HCFC}-141 \mathrm{~b}$ and $\mathrm{CO}_{2}$ were homogeneous corrosion. The corrosion rate of the former was slightly lower than that of the latter, but both were larger than deionized water.
\end{abstract}

Keywords: Thermal Insulation Materials, Aqueous Extract, A3 Steel, Corrosion Behavior, Static Weight Loss Method

\section{Introduction}

Corrosion under insulation (CUI) refers to the external corrosion of metals when they are encapsulated in thermal insulation. [1, 2] Up until the 1970s, CUI was not generally a problem. Economics at that time were such that piping, vessels, and equipment were not insulated unless the operating temperature was above $150^{\circ} \mathrm{C}(302 \mathrm{~F})$. Insulated steel surfaces that were $150^{\circ} \mathrm{C}$ or higher much of the time remained dry, so significant amounts of corrosion did not occur. [3] Problems with corrosion under thermal insulation (CUI) have been recognized by the chemical and petrochemical industries, leading to the need for effective corrosion protection for piping, vessels, and equipment encased in thermal insulation. From 40 to 60 percent of piping maintenance costs are related to CUI. [4] Statistics shows that over 60 percent of piping failure is caused by CUI in the petrochemical industries. [5] The global loss annually reaches up to billions of dollars due to a series of serious problems such as dangerous product leaks, equipment abnormal parking and even casualties caused by CUI triggering failure of equipment and pipelines. [6]
Thermal insulation materials are generally porous materials (capable of absorbing moisture), including mineral wool, foam glass, aerogels, and polymeric foams. It is the beginning of CUI that thermal insulation materials become wet as consequence of the entrance of water [7]. Most researchers believe that the reason of CUI occurred is the interaction of water, chemical content of water and temperature. [5, 8-10] Chloride and sulfate are the mainly corrosion products of CUI. $[11,12]$ Details on the mechanism of CUI see [13]. In this work, glass wool, silica aerogel insulation blankets, polyurethane foam expanded with HCFC-141b and polyurethane foam expanded with $\mathrm{CO}_{2}$ were selected to study. The physicochemical properties of aqueous extract of above materials were tested. They include $\mathrm{pH}$, conductivity and ions contents. Their corrosion behavior to A3 steel was investigated by static weight loss method. The purpose of this work was to provide reference for thermal insulation materials selection and corrosion control. 


\section{Materials and Methods}

\subsection{Experimental Materials}

The following materials were used for the experiments: glass wool, silica aerogel insulation blankets, polyurethane foam expanded with HCFC-141b, polyurethane foam expanded with $\mathrm{CO}_{2}$, deionized water and standard test piece of A3 steel. The materials used in this research conformed to the relative standards.

\subsection{Experimental Procedure}

Ten grams of each material were blended with $500 \mathrm{ml}$ deionized water. Statically and closed stored in $80^{\circ} \mathrm{C}$ for 1 day. The aqueous extract were obtained after filtering off the insoluble materials. Specimens were treated following the method in GB/T 18175-2014 «Determination of corrosion inhibition performance of water treatment agents-Rotation specimen method». 200ml hydrochloric acid, $800 \mathrm{ml}$ deionized water and $8 \mathrm{~g}$ hexamethylene tetramine were used to prepare the pickling solution. Standard test pieces of A3 steel were cleaned with filter paper. Scrubbed with degrease cotton in acetone and anhydrous ethanol respectively. Put on clean filter and soaked up. Dried for more than 4 hours. Weighted to $0.002 \mathrm{~g}$ accurately. Then put into $1800 \mathrm{ml}$ aqueous extract and immersed statically at room temperature for 60 days. Washed in the pickling solution for about $30 \mathrm{sec}$. Then took out. Washed quickly using running water. Immediately immersed in the hydroxide sodium solution $(60 \mathrm{~g} / 1)$ for about $30 \mathrm{sec}$. Took out, rinsed with distilled water and then wiped dry with filter paper. Immersed in ethanol for about $3 \mathrm{~min}$, put on clean filter and soaked up. Dried for more than 4 hours. Weighted to $0.2 \mathrm{mg}$ accurately. Original standard test piece of A3 steel was also treated as blank one. The corrosion rate was calculated and microstructure of A3 steel test piece was characterized.

\subsection{Experimental Design}

The experiments were designed to observe the corrosivity of thermal insulation materials aqueous extract and their corrosion behavior to A3 steel. The aqueous extract corrosivity was analyzed from $\mathrm{pH}$ value, conductivity and ions concentration. Behavior of corrosion to A3 steel was evaluated from corrosion rate and microstructure of A3 steel test piece. The corrosion rate $(\mu)$ was assumed equal to the rate of A3 steel test piece weight loss (Equation (1)).

$$
\mu=\frac{8760 \times\left(m-m_{0}\right) \times 10}{s \cdot \rho \cdot t}
$$

where $\mu=$ corrosion rate $(\mathrm{mm} / \mathrm{a})$

$\mathrm{m}=$ weight loss of test piece $(\mathrm{g})$

$\mathrm{m}_{0}=$ weight loss of blank test piece $(\mathrm{g})$

$\mathrm{s}=$ surface area of the specimen $\left(\mathrm{cm}^{2}\right)$

$\rho=$ density of the specimen $\left(\mathrm{g} / \mathrm{cm}^{3}\right)$

$\mathrm{t}=$ time $(\mathrm{h})$

\subsection{Physical and Chemical Analysis}

The aqueous extracts were analyzed for $\mathrm{pH}$ value and conductivity respectively by conductivity meter $\mathrm{S} 30$ and $\mathrm{pH}$ meter plus S20p of METTLER TOLEDO SevenEasy ${ }^{\text {TM }}$. In the $\mathrm{Mg}^{2+}, \mathrm{Ca}^{2+}$ and $\mathrm{SO}_{4}{ }^{2-}$ analysis, HACH DREL 2800 portable spectrophotometer was used. $\mathrm{CO}_{3}{ }^{2-}$ was tested with the method in GB/T 15451-2006 «Industrial circulating cooling water- Determination of total and composite alkalinity». $\mathrm{Cl}^{-}$ was detected using the method in GB/T 15453-2008 «Water for industrial circulating cooling system and boilerDetermination of chloride». 3D measuring laser microscope OLS 4000 of OLYMPUS was used to characterize microstructure of A3 steel test pieces.

\subsection{Chemicals}

The following chemicals were used for the experiments: acetone $\mathrm{CH}_{3} \mathrm{COCH}_{3}$ (AR, JIANGTIAN Chemical Co. Itd, Tianjin/ China), anhydrous ethanol $\mathrm{CH}_{3} \mathrm{CH}_{2} \mathrm{OH}$ (AR, BAISHI Chemical Co. ltd, Tianjin/ China), hydrochloric acid $\mathrm{HCl}$ (AR, FENGCHUAN Chemical Co. 1td, Tianjin/ China), hydroxide sodium $\mathrm{NaOH}$ (CR, FENGCHUAN Chemical Co. 1td, Tianjin/ China), hexamethylene tetramine $\mathrm{C}_{6} \mathrm{H}_{12} \mathrm{~N}_{4}$ (AR, FENGCHUAN Chemical Co. ltd, Tianjin/ China).

\section{Results and Discussion}

\subsection{Aqueous Extract Test Results}

Table 1 presents the physicochemical property test results. It included $\mathrm{pH}$, conductivity and ions contents of insulation materials and deionized water.

Table 1. The physicochemical property test results.

\begin{tabular}{|c|c|c|c|c|c|c|c|}
\hline $\begin{array}{ll}\text { Types } & \text { Items } \\
\end{array}$ & pH value & conductivity（ $\mu \mathrm{s} / \mathbf{c m})$ & $\mathrm{Mg}^{2+}(\mathrm{mg} / \mathrm{l})$ & $\mathrm{Ca}^{2+}(\mathrm{mg} / \mathrm{l})$ & $\mathrm{SO}_{4}{ }^{2-}(\mathrm{mg} / \mathrm{l})$ & $\mathrm{CO}_{3}{ }^{2-}(\mathrm{mg} / \mathrm{l})$ & $\mathrm{Cl}^{-}(\mathrm{mg} / \mathrm{l})$ \\
\hline deionized water & 7.12 & 2.46 & 0.06 & 0.37 & 0 & 0.00 & 0.89 \\
\hline glass wool & 8.97 & 699.12 & 0.67 & 0.13 & 51 & 36.18 & 3.99 \\
\hline silica aerogel insulation blankets & 6.39 & 15.69 & 0.07 & - & 0 & 0.00 & 0.89 \\
\hline $141 \mathrm{~b}$ system polyurethane foam & 7.95 & 17.04 & 0.07 & 0.44 & 0 & 0.00 & 0.89 \\
\hline entire water system polyurethane foam & 5.50 & 20.50 & 0.10 & 0.47 & 0 & 0.00 & 1.18 \\
\hline
\end{tabular}

The $\mathrm{pH}$ value between 7.0 and 8.0 is passive zone for A3 steel. In acidic environment, corrosion will increase because of the exiting of $\mathrm{H}^{+}$as a strong catholic depolarizer. The solution will be alkaline with $\mathrm{pH}$ value increasing. $\mathrm{CO}_{3}{ }^{2-}$ and
$\mathrm{OH}^{-}$will react with metal irons such as $\mathrm{Ca}^{2+}, \mathrm{Mg}^{2+}$ and so on in solution. Precipitates with poor adhesion are formed, which not only don't play the role of protecting metal but increase reaction area of cathodic depolarizer. As a result the 
dissolution of carbon steel is accelerated in the anode and corrosion increases [14]. Table 1 shows that the aqueous extract of glass wool is alkaline and that of silica aerogel insulation blankets and the entire water system polyurethane foam are acidic. If metal irons such as $\mathrm{Ca}^{2+}, \mathrm{Mg}^{2+}$ and so on are in the solution, the corrosivity to A3 steel of above aqueous extract is higher. The $\mathrm{pH}$ value of the aqueous extract of $141 \mathrm{~b}$ system polyurethane foam is in the passive zone for A3 steel and its corrosivity is lower.

Corrosivity of aqueous extract has a certain relationship with conductivity. The bigger the conductivity, the more chance the macroscopic corrosion of metal surface happens and pitting is easier focus on individual areas [15]. Table 1 shows that the conductivity of glass wool aqueous extract is the largest, up to $699.12 \mu \mathrm{s} / \mathrm{cm}$. That of silica aerogel insulation blankets aqueous extract, $141 \mathrm{~b}$ and the entire water system polyurethane foam aqueous extract are similar, which are respectively $15.69,17.04$ and $20.50 \mu \mathrm{s} / \mathrm{cm}$, largely smaller than that of glass wool aqueous extract. From the relationship between aqueous extract conductivity and corrosivity, glass wool aqueous extract easily causes localized corrosion.

When concentration is small in alkaline environment, $\mathrm{Mg}^{2+}$ easily forms precipitates with poor adhesion, which increase corrosion. If concentration is larger, the integrity of precipitates surface is good and it can inhabit corrosion. Table 1 shows that the concentration of $\mathrm{Mg}^{2+}$ is $0.67 \mathrm{mg} / \mathrm{l}$ in glass wool aqueous extract and lower than $0.1 \mathrm{mg} / \mathrm{l}$ in the other 3 kinds of aqueous extract. The concentration of $\mathrm{Mg}^{2+}$ in 4 kinds of aqueous extract is small. The glass wool aqueous extract is alkaline. The effect of $\mathrm{Mg}^{2+}$ on corrosivity of glass wool aqueous extract is the largest.

The action principle of affection of $\mathrm{Ca}^{2+}$ on corrosion is similar to that of $\mathrm{Mg}^{2+}$. When there are no anions reacting with $\mathrm{Ca}^{2+}$ to precipitate in liquid, the effect of $\mathrm{Ca}^{2+}$ on corrosion of carbon steel is small. If there are anions reacting with $\mathrm{Ca}^{2+}$ to precipitate in alkaline environment, $\mathrm{CaCO}_{3}$ particles deposited on the surfaces of metal may become pitting source that can induce pitting and localized corrosion [16]. When the concentration of $\mathrm{Ca}^{2+}$ is large in solution, the integrity of $\mathrm{CaCO}_{3}$ surface is good and it can inhabit corrosion. Table 1 shows that the concentration of $\mathrm{Ca}^{2+}$ is $0.13 \mathrm{mg} / \mathrm{l}$ in glass wool aqueous extract. It isn't detected in silica aerogel insulation blankets aqueous extract. That of the $141 \mathrm{~b}$ system and the entire water system polyurethane foam aqueous extract are similar, respectively 0.44 and $0.47 \mathrm{mg} / \mathrm{l}$. The glass wool aqueous extract is alkaline and the concentration of $\mathrm{Ca}^{2+}$ is relatively small which can easily cause pitting and localized corrosion.

$\mathrm{SO}_{4}{ }^{2-}$ also has some influence on the pitting corrosion of carbon steel. When its concentration is low, the competitive adsorption to $\mathrm{Cl}^{-}$may lead to high concentration of $\mathrm{Cl}^{-}$ localized, which accelerates pitting. When the concentration increases to a certain extent, $\mathrm{Cl}^{-}$can no longer largely concentrate in a local, then pitting is inhabited [16]. The concentration of $\mathrm{SO}_{4}{ }^{2-}$ is $51 \mathrm{mg} / \mathrm{l}$ in glass wool aqueous extract and it isn't detected in the other 3 kinds of materials aqueous extract. Therefore glass wool aqueous extract more likely causes pitting of carbon steel.

The principle of effect of $\mathrm{CO}_{3}{ }^{2-}$ on corrosion is relative with that of $\mathrm{Ca}^{2+}$. Their effect on corrosion depends on the $\mathrm{pH}$ value and their concentration. Deposited film of $\mathrm{FeCO}_{3}$ and $\mathrm{Fe}_{2}\left(\mathrm{CO}_{3}\right)_{3}$ formed by $\mathrm{CO}_{3}{ }^{2-}$ reaction with metal ions dissolved from carbon anode, mainly $\mathrm{Fe}^{2+}$ and $\mathrm{Fe}^{3+}$, hinder the further reaction of anode [17]. Table 1 shows that in 4 kinds of materials aqueous extract, $\mathrm{CO}_{3}{ }^{2-}$ is only detected in glass wool aqueous extract and the concentration is $36.18 \mathrm{mg} / \mathrm{l}$.

The $\mathrm{Cl}$ - in solution usually plays a crucial role in pitting initiation [18, 19], and most environment materials' pitting associated with $\mathrm{Cl}^{-}$[20]. Many efforts have been made to explain the pitting initiation of metal in chloride-containing solutions [21-31]. $\mathrm{Cl}^{-}$can destroy the passive film on the surface of A3 steel generated by corrosion, which making steel surface always in the activated state. In addition, active carbon steel surface can react with $\mathrm{Cl}^{-}$to chloride, which is a strong alkali and weak acid salt. It easily hydrolyzes to hydrogen ions and decreases the $\mathrm{pH}$ value of corrosion surface, which promotes the corrosion of carbon steel [17]. Table 1 shows that the concentration of $\mathrm{Cl}^{-}$is $3.99 \mathrm{mg} / \mathrm{l}$ in glass wool aqueous extract, which is the largest in 4 kinds of materials aqueous extract. The entire water system polyurethane foam aqueous extract follows by. Compared with the concentration of $\mathrm{Cl}^{-}$in deionized water, that of $141 \mathrm{~b}$ system polyurethane foam and silica aerogel insulation blankets aqueous extract is $0 \mathrm{mg} / \mathrm{l}$. It can be inferred that localized corrosion is the performance of glass wool aqueous extract to A3 steel.

\subsection{Corrosion Rate Results}

Corrosion rate of different kinds of aqueous extract and deionized water to A3 steel are calculated by Equation (1). The results are shown in Table 2 .

Table 2. Corrosion rate calculation results $\left(\times 10^{-4} \mathrm{~mm} / \mathrm{a}\right)$.

\begin{tabular}{lllll}
\hline Type of aqueous extract & deionized water & glass wool & $\begin{array}{l}\text { silica aerogel insulation } \\
\text { blankets }\end{array}$ & $\begin{array}{l}\text { 141b system } \\
\text { polyurethane foam }\end{array}$ \\
\hline Corrosion rate & 3.49 & 0.56 & 2.83 & 3.63 \\
\hline
\end{tabular}

From the results shown in Table 2, it can be concluded that corrosion rate of both glass wool and silica airgel insulation blankets aqueous extract to standard test piece of A3 steel is lower than that of deionized water. That of glass wool aqueous extract is the lowest and that of the entire water system polyurethane foam aqueous extract is the highest.

\subsection{Microstructure of Immersed A3 Steel Standard Test Pieces}

Microstructure of A3 steel standard test pieces was characterized by 3D measuring laser microscope OLS 4000 of OLYMPUS. Local magnification of test piece is 100 times. 
That of Figure $2 b$ is 200 times. (a) is the overall morphology after immersing. (b), (c) and (d) are local morphology.

Microstructure of test piece immersed in deionized water is shown in Figure 1. From Figure 1 it can be observed that the corrosion performance of deionized water to A3 steel standard test piece is homogeneous corrosion. The corrosion of thread covered area (c) and edge (d) isn't obvious.

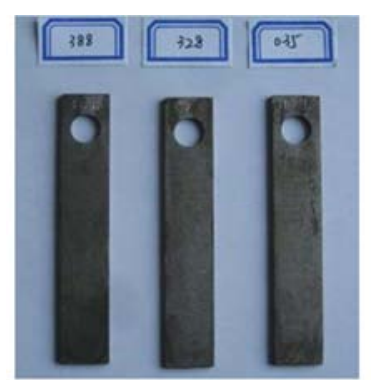

(a)

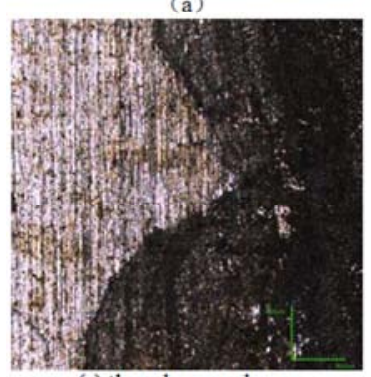

(c) thread covered area

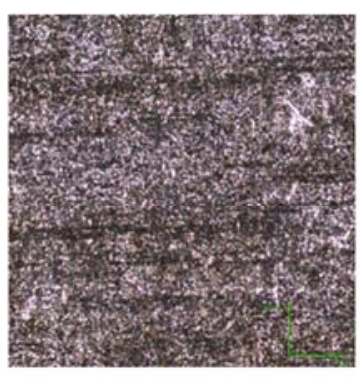

(b) corrosion area

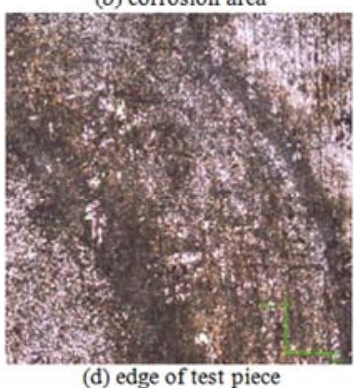

(d) edge of test piece
Figure 1. Microstructure of specimens immersed in deionized water.

Microstructure of test piece immersed in glass wool aqueous extract is shown in Figure 2. From Figure 2, it can be concluded that the corrosion performance of glass wool aqueous extract to A3 steel is local corrosion. The corrosion of thread covered area and near the hang up end is obvious. The remaining parts are not obvious.

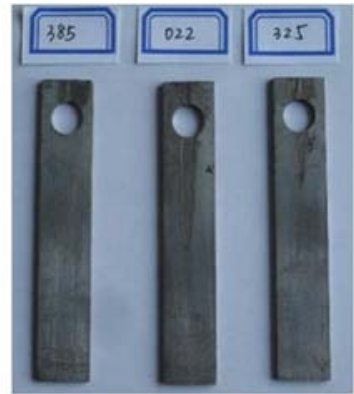

(a)

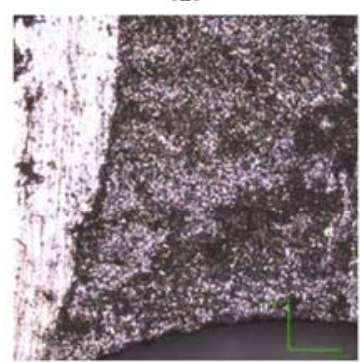

(c) lower edge of hang up hole
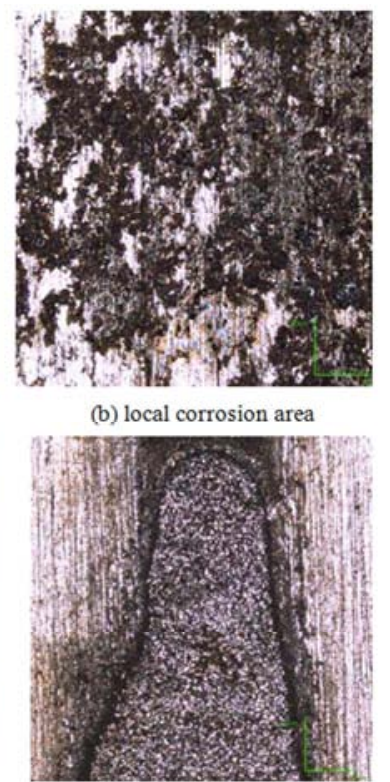

(d) bottom of local corrosion under hang up hole (b) local corrosion area

Figure 2. Microstructure of specimens immersed in glass wool aqueous extract.
Microstructure of specimens immersed in silica aerogel insulation blankets aqueous extract is shown in Figure 3. It can be found that the corrosion performance of silica aerogel insulation blankets aqueous extract to A3 steel is homogeneous corrosion. As shown in Figure 3c and 3d, the corrosion of thread covered area isn't obvious.
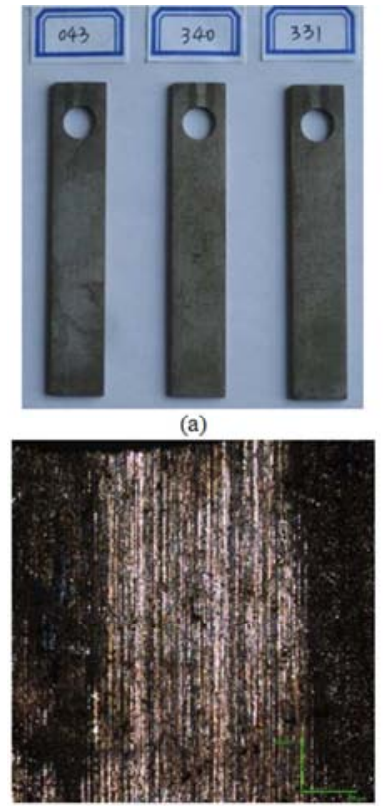

(c) thread covered area

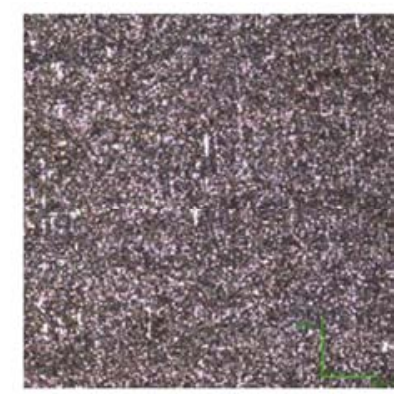

(b) corrosion area

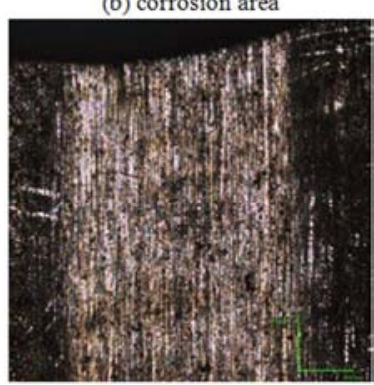

(d) thread covered area
Figure 3. Microstructure of specimens immersed in silica aerogel insulation blankets aqueous extract.

Figure 4 shows the microstructure of specimens immersed in aqueous extract of polyurethane foam expanded with HCFC-141b. The corrosion behavior performs homogeneous corrosion. The corrosion of the edges is not obvious, as shown in Figure 4c and $4 d$.

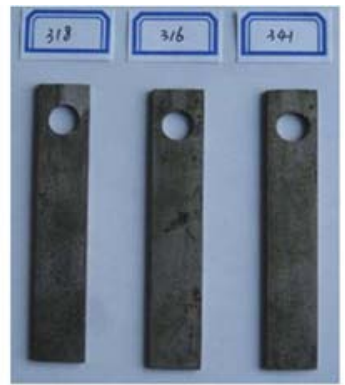

(a)

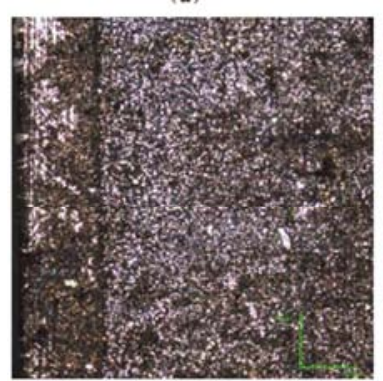

(c) edge of the specimen

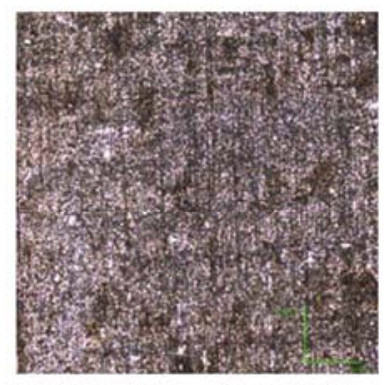

(b) corrosion area

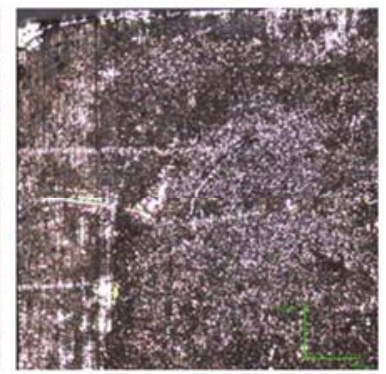

(d) edge of the specimen
Figure 4. Microstructure of specimens immersed in HCFC-141b polyurethane foam aqueous extract. 
Figure 5 shows the microstructure of specimens immersed in aqueous extract of polyurethane foam expanded with $\mathrm{CO}_{2}$. It can be concluded that the corrosion performance is homogeneous corrosion. As shown in Figure $5 \mathrm{c}$ and $5 \mathrm{~d}$, corrosion of one side of top specimen is not obvious.

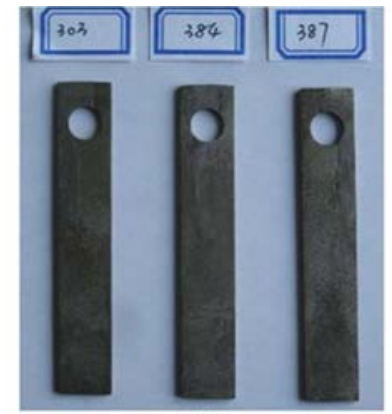

(a)

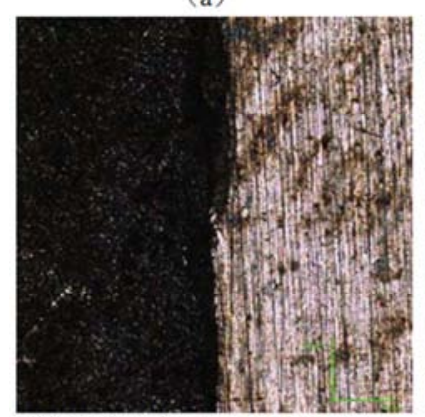
of specimen (c) interface of corrosion on the top

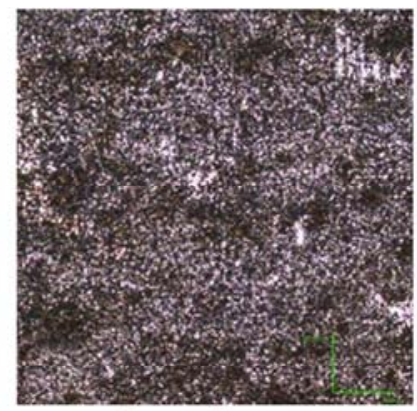

(b) corrosion area

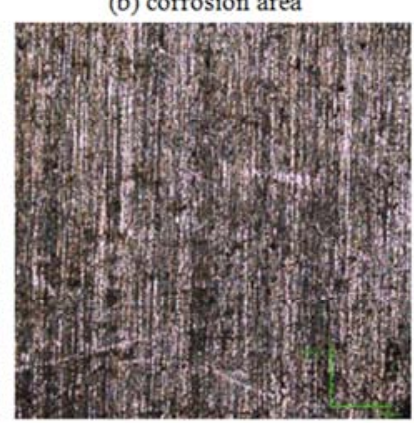

(d) inconspicuous corrosion area
Figure 5. Microstructure of specimens immersed in $\mathrm{CO}_{2}$ polyurethane foam aqueous extract.

\section{Conclusion}

The following conclusions are obtained from thermal insulation materials aqueous extract test and static coupon test.

The aqueous extract of glass wool is alkaline and the conductivity is larger. There are $\mathrm{Ca}^{2+}, \mathrm{CO}_{3}{ }^{2-}, \mathrm{SO}_{4}{ }^{2-}$ and $\mathrm{Cl}^{-}$in the aqueous extract. The corrosion rate to $\mathrm{A} 3$ steel is the lowest but corrosion behavior performs local corrosion, the danger of which is the highest.

The aqueous extract of silica aerogel insulation blankets is acidic and the conductivity is $20.50 \mu \mathrm{s} / \mathrm{cm} \mathrm{SO}_{4}{ }^{2-}$ and $\mathrm{CO}_{3}{ }^{2-}$ are not detected in the aqueous extract. Compared with the concentration of $\mathrm{Cl}^{-}$in deionized water, that of silica aerogel insulation blankets aqueous extract is $0 \mathrm{mg} / \mathrm{l}$. The corrosion is homogeneous. The corrosion rate is lower than that of deionized water.

The aqueous extract of polyurethane foam expanded with $\mathrm{CO}_{2}$ is alkaline while that of HCFC-141b polyurethane foam is acidic. $\mathrm{SO}_{4}{ }^{2-}$ and $\mathrm{CO}_{3}{ }^{2-}$ are not detected in both kinds of aqueous extract. Corrosion performance is homogeneous. The former is lower than the later on conductivity, concentration of $\mathrm{Mg}^{2+}, \mathrm{Ca}^{2+}$ and $\mathrm{Cl}^{-}$and corrosion rate to $\mathrm{A} 3$ steel.

Some suggestions are given to reduce corrosion under insulation:

(1) Avoiding water into insulation material is the precondition of reducing corrosion under insulation. Waterproof and seal must be done well for thermal insulation works.

(2) Metal body shouldn't be used barely under insulation. Before insulation, preservative treatment must be done. When water comes into insulation layer, aqueous extract couldn't contact with metal directly.

(3) Hydrophobic or low water absorption insulation materials are selected as far as possible.

(4) For the ground insulation works, parts of which the water easily comes in should be checked regularly. Problems discovered must be treated in time.

\section{References}

[1] JIANG Ying-jie, GONG Jian-ming, TANG Jian-qun. "Current Status of Research on Corrosion of Metallic Materials beneath Insulation Coat" $[\mathrm{J}]$. Corrosion Science and Protection Technology, 2011, 23(5): 381-386.

[2] Naing Naing Aung, Wong Keng Wai, Yong-Jun Tan. "A novel electrochemical method for monitoring corrosion under insulation". Anti-Corrosion Methods and Materials, 2006, 53 (3): $175-179$.

[3] Goldie Brian, Kapsanis Karen. "Corrosion under Insulation: Basics and Resources for Understanding", Journal of Protective Coatings \& Linings, Pittsburgh (Jul 2009): 34-37.

[4] Michael Lettich, "Is there a cure for corrosion under insulation?" Insulation Outlook, November 2005.

[5] LÜ Xiao-liang, TANG Jian-qun, ZHU Jian-ming, ect. "Current Status of Research on Corrosion Prevention of Metallic Materials Beneath Insulation Coat" Corrosion Science and Protection Technology, 2014, 26(2):167-172.

[6] Fitzgerald B J, Winnik S. "A corrosion under insulation prevention strategy for petrochemical industry piping”. Corros. Manag, 2004, 57(1): 15.

[7] F. V. V. de Sousa, R. O. da Mota, J. P. Quintela, etc. "Characterization of corrosive agents in polyurethane foams for thermal insulation of pipelines". Electrochimica Acta, 2007, 52:7780-7785.

[8] Frank De Vogelaere. "Corrosion under insulation" Process Safety Progress, March 2009, Vol.28, No.1,p.30-35.

[9] Shekari E, Khan F, Ahmed S. "Probabilistic Modeling of Pitting Corrosion in Insulated Components Operating in Offshore Facilities" ASCE-ASME Journal of Risk and Uncertainty in Engineering Systems, MARCH 2017, Vol. 3, pp.011003-1- 011003-11.

[10] Geary W, Parrott R. "Two corrosion under insulation failure case studies”, Loss Prevention Bulletin, 2016, 250(8): 2-6.

[11] Delahunt J F. "Corrosion under thermal insulation and fireproofing an overview [A]". Corrosion 2003 [C]. San Diego: NACE, 2003, 03022.

[12] Goldie B, Kapsanis K. "Corrosion under insulation: Basics and resources for understanding ". JPCL, 2009, 6: 34.

[13] Srinivasan, S., Ellis, II, P. F., Chauviere, M. M \& Kane, R. D: "Can we better address CUI and energy loss?", Material Performance, Vol. 52, No. 1, 2013. 
[14] XIE Zhi-hai, LI Li, JIANG Xiao-yan, etc. "Study of the corrosion behavior of A3 carbon steel in simulated oilfield water". Applied Chemical Industry, 2010, 39(9): 1293-1299.

[15] WENG Yong-ji. "Corrosion of Steel Pipelines in wet thermal insulation materials". Metal Material, 1989, 7-13.

[16] Xu Li-ming, Luo Yi, DONG Ze-hua, etc. "The Influence of Calcium Ions on Corrosion of Mild Carbon Steel in Oilfield Produced Water ". Oilfield Chemistry, 1996, 13(2): 161-164.

[17] AN Yang. "Study on Behaviors of The Corrosion of Stainless Steel and Carbon Steel in Circulating Cooling Water". Tianjin: Tianjin University, 2010.

[18] Bin Lin, Ronggang Hu, Chenqing Ye, etc. "A study on the initiation of pitting corrosion in carbon steel in chloride-containing media using scanning electrochemical probes ". Electrochimica Acta, 2010, 55: 6542-6545.

[19] Noveiri E, Torfi S. "Nano coating application for corrosion reduction in oil and gas transmission pipe: A case study in south of Iran". IJSEI, 2012, 1(2): 104.

[20] JIANG Tao. "Study on Pitting Corrosion of Carbon Steel by Electrochemical Methods in Alkaline Solutions". Beijing: Beijing University of Chemical Technology, 2000.

[21] D. Sazou, A. Diamantopoulou, M. Pagitsas, Electrochimica Acta, 2000, 45 (17):2753-2769.

[22] Z. Szklaraska-Smialowska, Corrosion (Houston), 1971, 27, 223.

[23] Y. M. Kolotyrkin, Y. A. Popov, Y. V. Alekseev, in: Y. M. Kolotyrkin (Ed.), "Advances in Physical Chemistry: Current Developments in Electrochemistry and Corrosion", Moscow: Mir Press, 1982, p. 11.
[24] S. M. Sharland, "A review of the theoretical modelling of crevice and pitting corrosion", Corros. Sci. 1987, 27 (3): 289-323.

[25] Sato N. "Toward a more fundamental understanding of corrosion processes". Corrosion, 1989, 45(5): 354.

[26] H. H. Strehblow, P. Marcus, J. Oudar (Eds.), "Corrosion Mechanisms in Theory and Practice", Marcel Dekker, New York, 1995, 201.

[27] Bastos A C, Simoes A M, Souto R M. "Imaging concen- tration prooles of redox-active species in open-circuit corrosion processes with the scanning electrochemical microscope". Electrochem. Commun., 2004, 6(11): 1212-1215.

[28] Caines S, Khan F, Shirokoff J. "Analysis of Pitting Corrosion on Steel under Insulation in Marine Environments" Journal of Loss Prevention in the Process Industries, 2013, 26 (6): 1466-1483.

[29] Frankel G S, Sridhar N, "Understanding Localized Corrosion", Mater. Today, 2008, 11(10):38-44.

[30] Pardo A, Otero E, Merino M C and etc, "Influence of $\mathrm{pH}$ and Chloride Concentration on the Pitting and Crevice Corrosion Behavior of High-Alloy Stainless Steels", Corrosion, 2000, 56(4):411-418.

[31] Matsch S, Boehni H. "Electrochemical Investigations of Pitting Events at Different Temperatures by Current Transients Analysis Pits Pores Formation Properties, and Significance Advanced Material Proceeding International Symposium", Vol. 25, Schmuki P., ed., Electrochemical Society, Pennington, NJ, 2000, pp. $70-74$. 